Relationship between Work-Family Balance and Job Performance among Academics in Sri Lanka

by

Vidyanee Vithanage

A thesis submitted to the University of Sri

Jayewardenepura in partial fulfillment of the requirements for the Degree of Master of Science in Management on $11^{\text {thth }}$ May 2015 


\section{Declaration}

The work described in this thesis was carried out by me under the supervision of $\mathrm{Dr}$

(Mrs) Bhadra Arachchige and a report on this has not been submitted in whole or in part to any university or any other institution for another Degree/ Diploma.

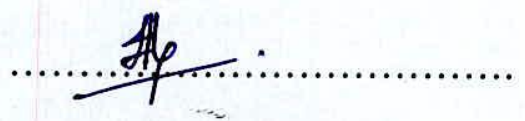

Vidyanee Vithanage

(5266FM2011098)

Date: ...1!.:0.5:2.:.15 


\section{Recommendation of the Supervisor for the Thesis}

I certify that the above statement made by the candidate is true and that this thesis is suitable for submission to the university for the purpose of evaluation.

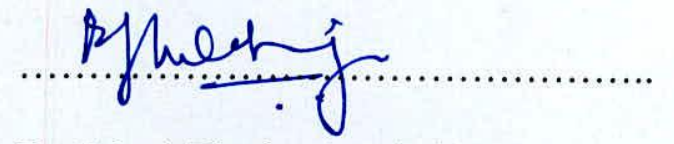

Dr (Mrs.) Bhadra Arachchige

Senior Lecturer

Department of Human Resource Management

Faculty of Management Studies and Commerce

University of Sri Jayewardenepura

Date: ..........05 . 2015 


\section{Table of Contents}

List of Tables ...................................................................................................................... VIII

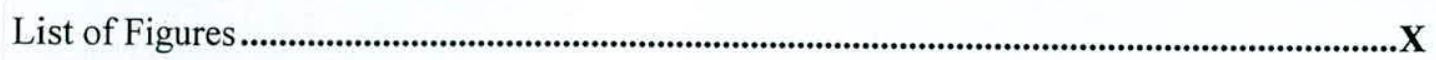

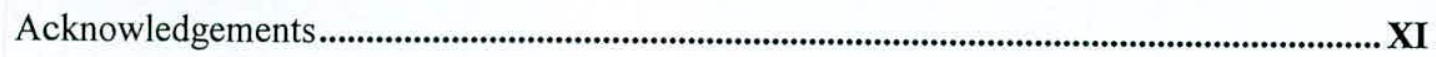

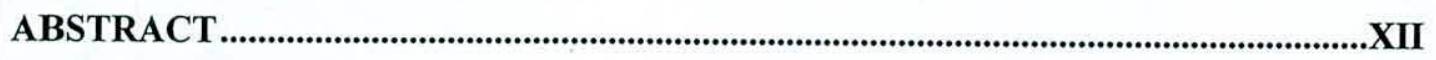

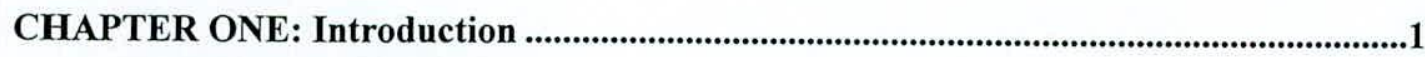

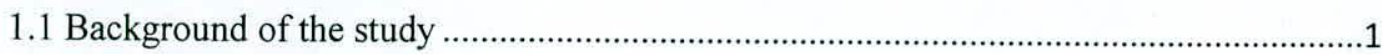

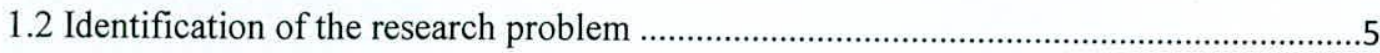

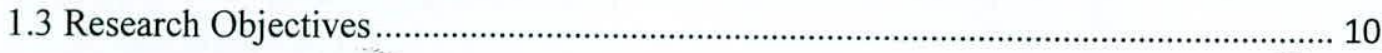

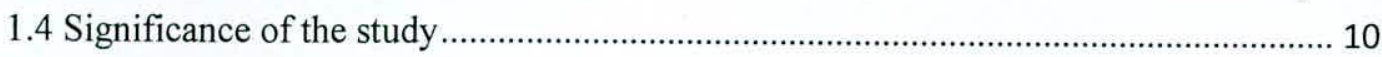

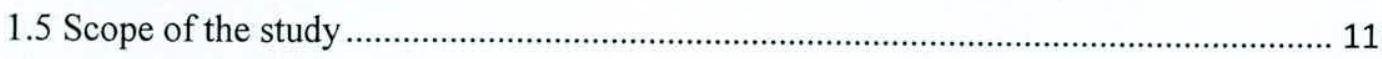

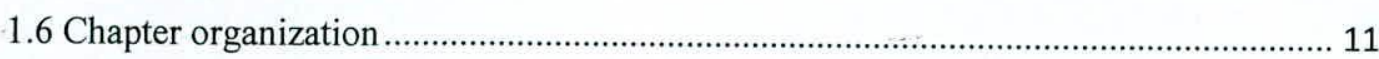

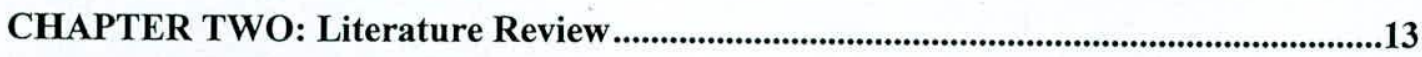

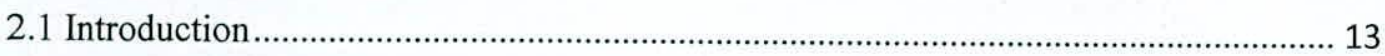

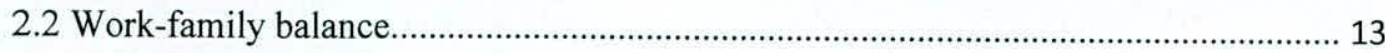

2.2.1 Defining work, family and work-family balance ...................................................... 14

2.2.2 Emergence of the concept of work-family balance...................................................... 14

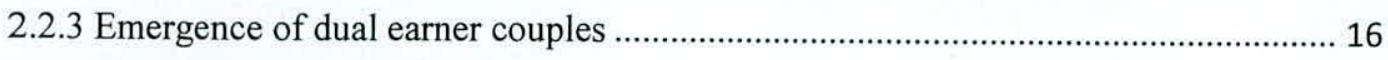

2.2.4 Marital partnership and work-family balance ......................................................... 17

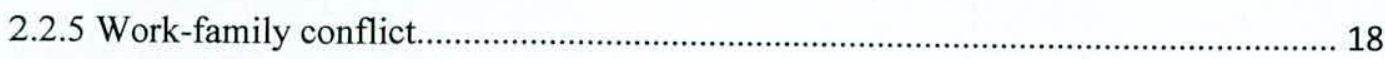

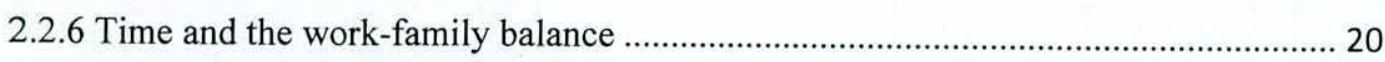

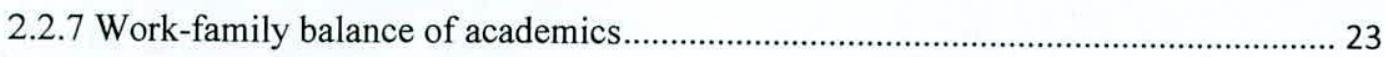

2.2.8 Gender differences in balancing work and family spheres ...................................... 27

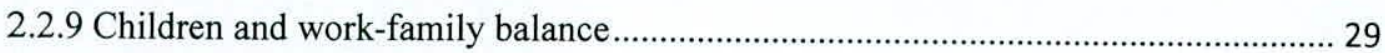

2.2.10 Conceptualizing work-family balance .................................................................... 35

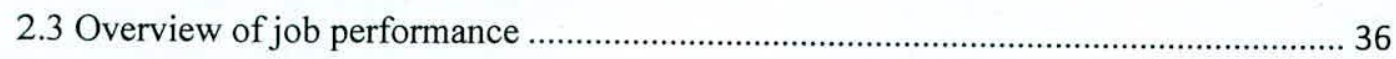

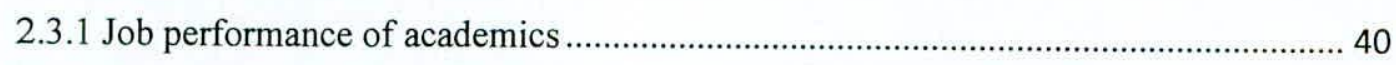

2.3.2 Relationship between work-family balance and job performance .............................. 42

2.3.3 Academics and the relationship between work-family balance and job performance 43

2.3.3 Impact of family friendly policies on work-family balance....................................... 48 
CHAPTER THREE: Conceptualization and Operationalization ....................................55

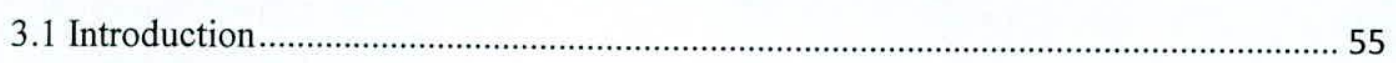

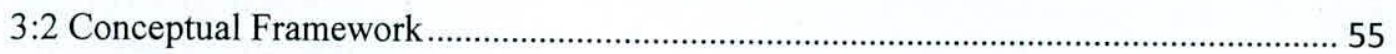

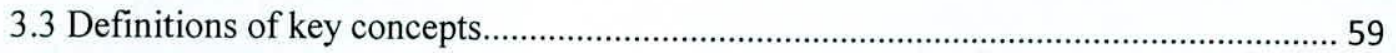

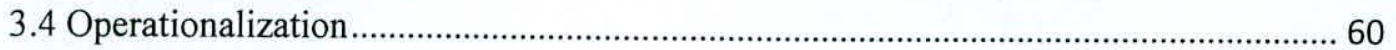

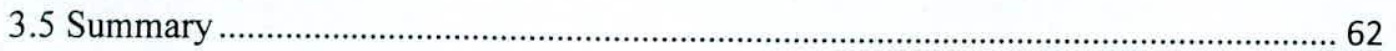

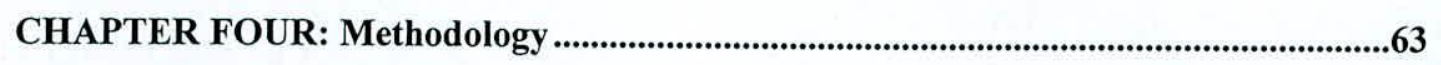

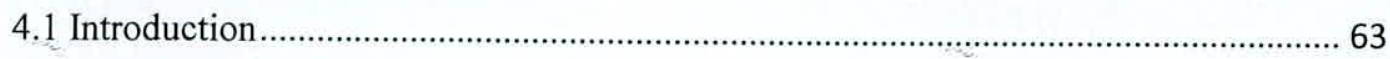

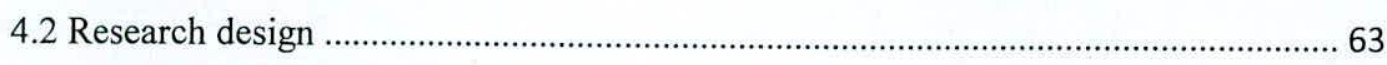

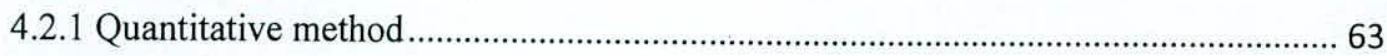

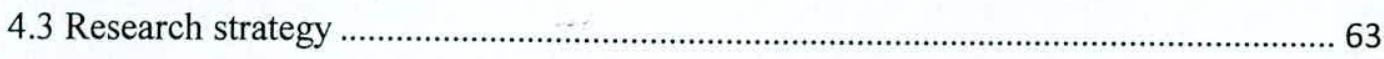

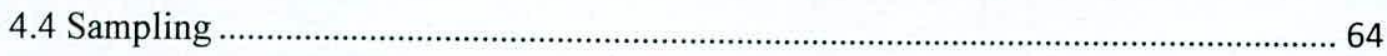

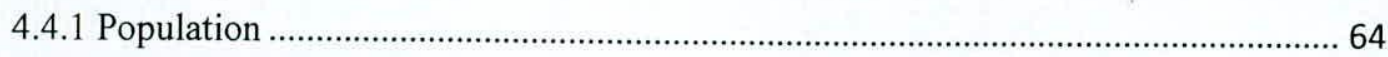

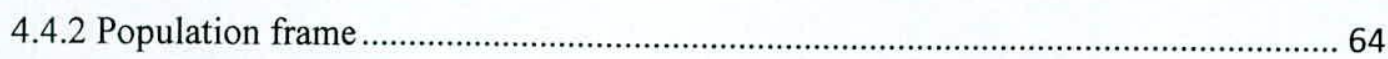

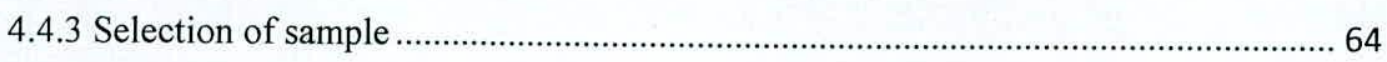

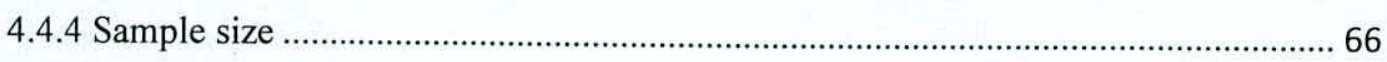

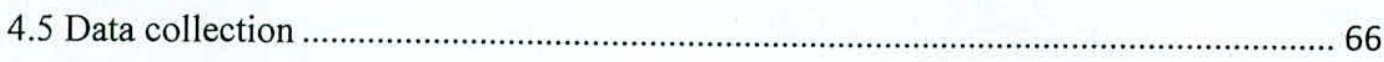

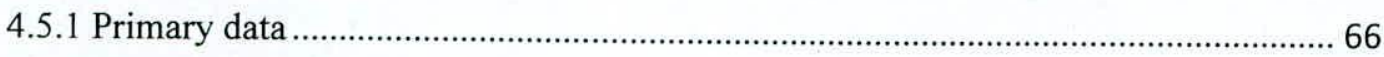

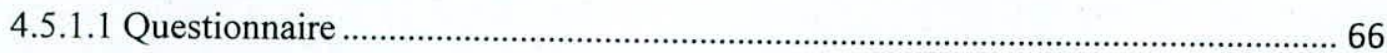

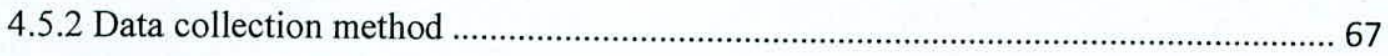

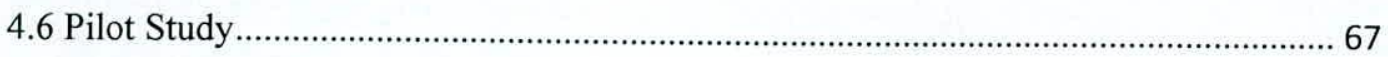

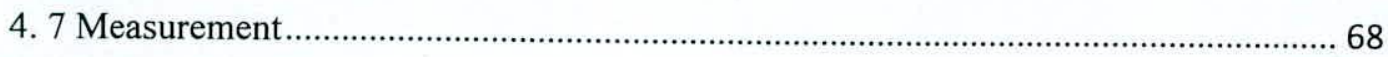

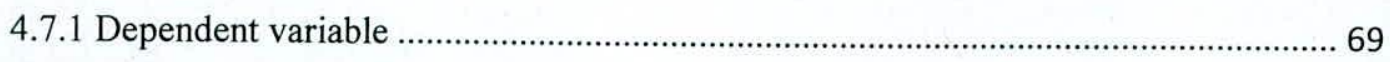

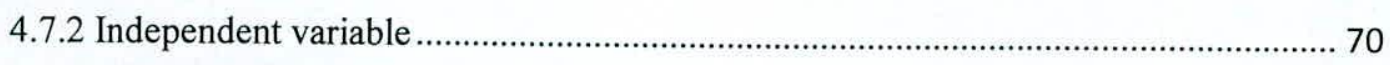

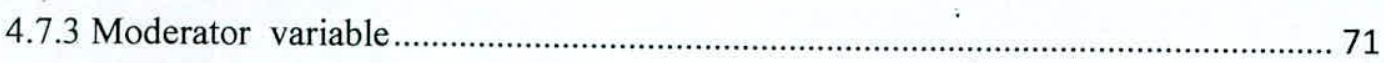

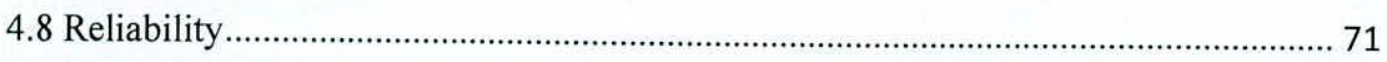

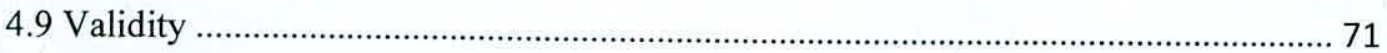

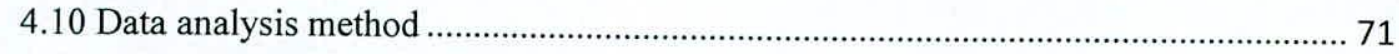

4.10.1 Partial Least Square Path Modeling (PLS) ….......................................................... 72

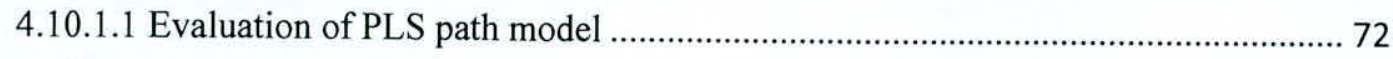




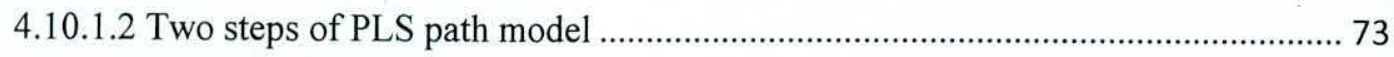

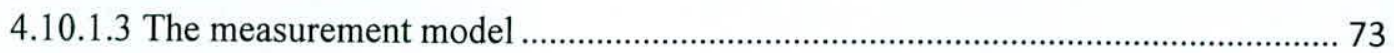

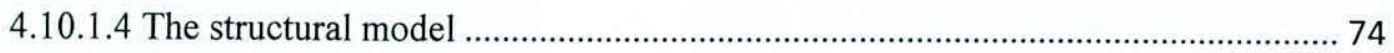

4.10.2 Statistical Package for the Social Sciences (SPSS) …............................................... 75

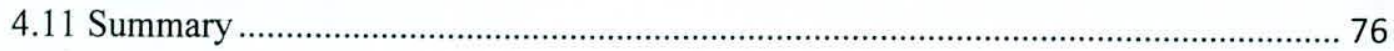

CHAPTER FIVE: Data Presentation and Analysis..............................................................77

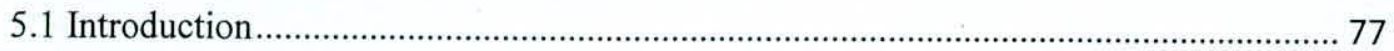

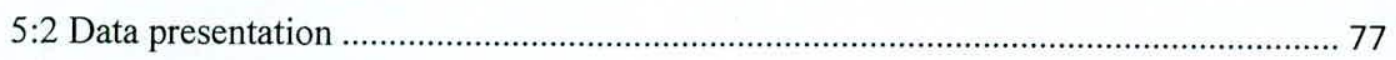

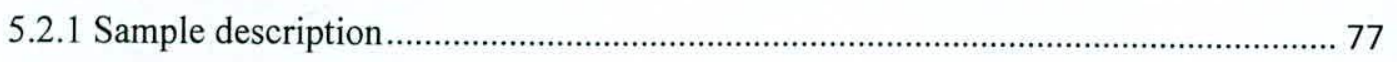

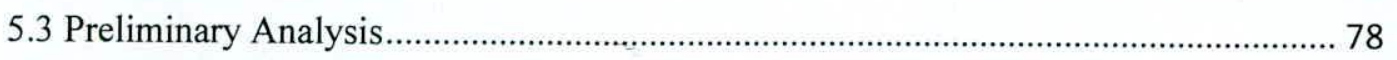

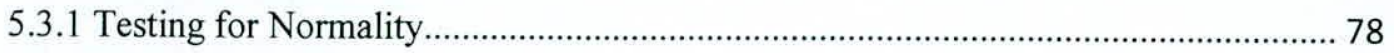

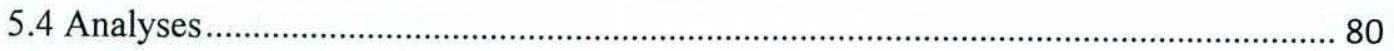

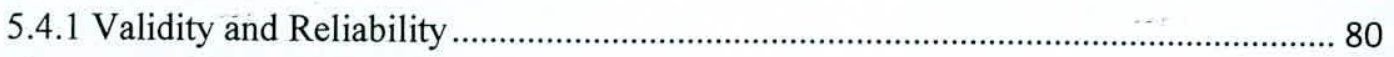

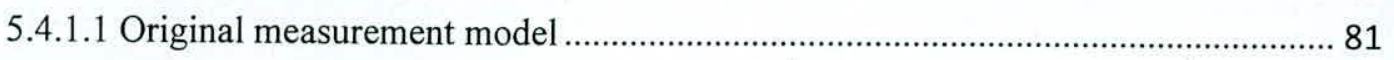

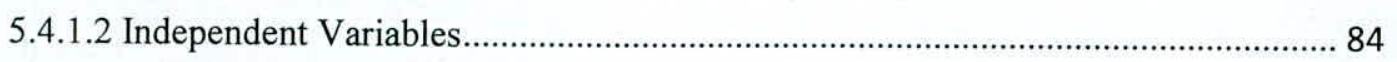

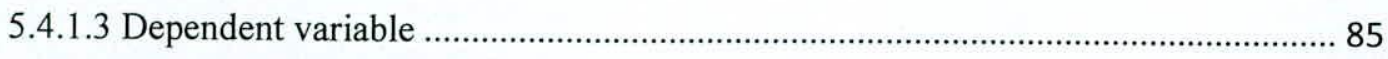

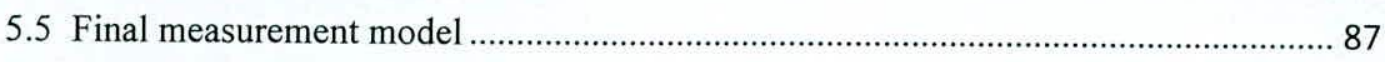

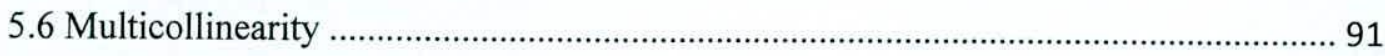

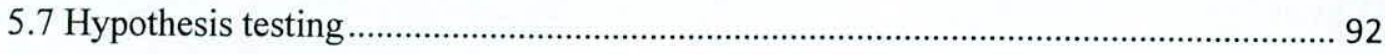

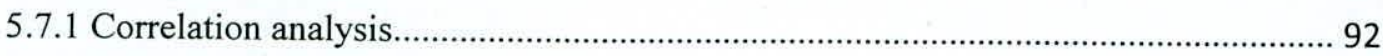

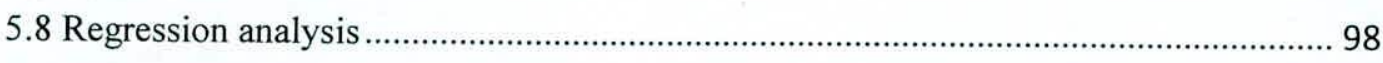

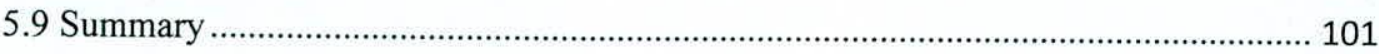

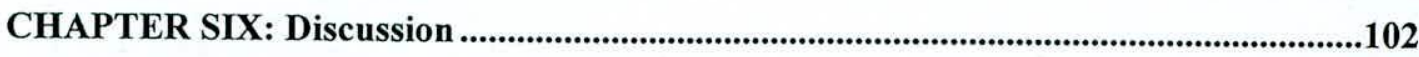

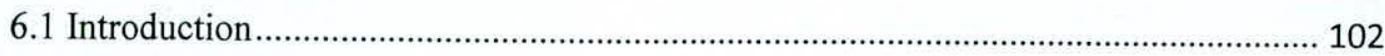

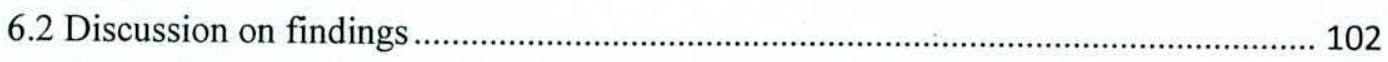

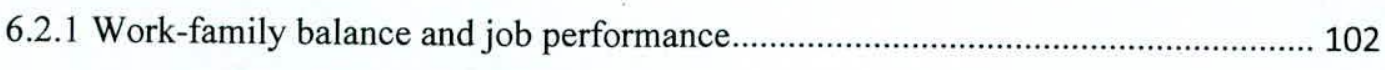

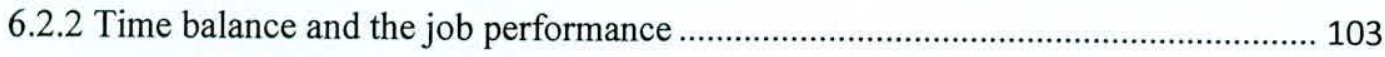

6.2.3 Involvement balance and job performance ….......................................................... 104

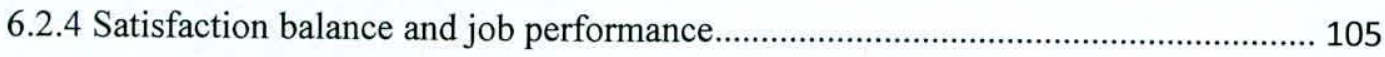

6.2.5 Moderating effect of gender on work-family balance and job performance............. 105

6.2.6 Moderating effect of marital Status on work-family balance and job performance 107 
6.2.7 Moderating effect of dependent Children on work-family balance and job performance.

6.3 Summary 109

CHAPTER SEVEN: Summary and Conclusion............................................................ 110

7.1 Overall summary

7.2 Theoretical implications.

7.3 Empirical implications.

7.4 Further Research

7.5 Limitations

7.6 Conclusion

References

Appendix 1 - Preliminary survey questionnaire. XIV

Appendix 2 - Covering Letter XVI

Appendix 3- Main survey questionnaire. XVII 


\section{List of Tables}

No.

Table 2.1

Table 3.1

Table 4.1

Table 4.2

Table 4.3

Table 5.1

Table 5.2

Table 5.3

Table 5.4

Table 5.5

Table 5.6

Table 5.7

Table 5.8

Table 5.9

Table 5.10

Table 5.11

Table 5.12

Table 5.13

Table 5.14

Table 5.15

Table 5.16

Table 5.17

Table 5.18
Name of Table

Page

Phases of changing composition of work and family

life spheres

Operationalization of variables

60

Number of Academics in Management Faculties by

65

University

Assessing the measurement Model

Assessing the structural Model 74

Demographic characteristics of the sample 78

The skewness and kurtosis of variables 79

Statistical summary of variables 80

Confirmatory factor analysis of original measurement 81 model

Confirmatory factor analyses of constructs

Discriminant validity of the latent variables

Statistics of multicollinearity

Correlation analysis

92

Model summary: Moderator effect of Gender 93

ANOVA 94

Coefficients 94

Model summary: Moderator effect of Marital Status 95 ANOVA 95

Coefficients 96

Model summary: Moderator effect of Dependent 97 children

\section{ANOVA}

Coefficients

Model summary: Work-family balance and job 98

performance 
Table 5.19

Coefficients

Table 5.20

Model summary: Time balance, Involvement balance

Satisfaction balance and Job performance

Table 5.21

Coefficients

100 


\section{List of Figures}

No.

Name of the Figure

Page

Figure 3.1

Conceptual framework

55

Figure 4.1

Two steps of PLS path model

73 


\section{Acknowledgements}

There are a few people that I would like to thank with all my heart, as without them this attempt would have been mere imagination.

I thank my thesis Supervisor Dr (Mrs) Bhadra Arachchige, for being interested and enthusiastic about my thesis. Her immense support, kindness, courage and the belief in my abilities helped me to fulfill a dream into reality. I truly appreciate the way she guided me, advised me and set me free throughout my endeavors.

I thank Dr Janak Kumarasinghe, the coordinator of the MBA/MSc program for his invaluable advices and guidance which was very helpful for completion of the thesis. I also thank the academic staff of the Management Faculties of the University of Sri Jayewardenepura, University of Colombo, University of Kelaniya and the University of Ruhuna for giving their fullest cooperation as participants of the research. I thank to my friends, Mrs. Lakmali Jayaratne and Mr. Sampath Kongahaarachchi for giving their kind support as true friends in data collection which was the hardest part of this research.

My sincere thanks to Mrs. M Janz, for all the assistance rendered to me in relation to the editing.

Most important, I am thankful to my beloved parents, Mrs. Manel Indra Seneviratne and Mr. Somapala Vithanage and my husband, Mr. Kelum Wannige who have always been proud of me and believed that I can do anything that I put my mind to. 


\title{
Relationship between Work-family balance and Job Performance among Academics in Sri Lanka
}

\author{
by

\section{Vidyanee Vithanage}

\begin{abstract}
Work-family balance and job performance are important aspects in the lives of individuals. Especially for the working group the issue of the balance between work life and family life has a relationship to job performance. The literature shows a gap between the Sri Lankan and international situation regarding the relationship between work-family balance and job performance of university academics. Hence, to fulfill this research gap this study focused to find an answer for the above problem in relation to the Sri Lankan context. As the main research objective of this study was to investigate the relationship between university academics' work-family balance and job performance. Further, this study aimed to find the dimensional impact of work-family balance on job performance of university academics. Then this study was to investigate the moderating effect of gender, marital status and dependent children on the relationship between work-family balance and job performance.
\end{abstract}

With the purpose of accomplishing the aforesaid objectives, a self administered survey was carried out among 196 university academics who belong to the University of Sri Jayawardenapura, University of Colombo, University of Kelaniya and the University of Ruhuna. A structured questionnaire was used for the primary data collection. In this current research study, work-family balance functioned as the independent variable and job performance was the dependent variable. Time balance, involvement balance and the satisfaction balance were the three selected dimensions of work-family balance and 
task performance, contextual performance and adaptive performance were the three dimensions of job performance. Further, this study used gender, marital status and dependent children as moderating variables. This study employed confirmatory factor analysis, correlation analysis, hierarchical multiple regression analysis and regression analysis.

This research study has found a statistically significant positive relationship between work-family balance and job performance among academics. It was also found that a statistically significant relationship existed between work-family balance dimensions and job performance. Further, it was revealed that gender has a statistically significant positive moderating effect on the relationship between work-family balance and job performance, while having marital status and dependent children has no significant moderating effect on the relationship between work-family balance and job performance. The multiple regression analysis revealed satisfaction balance as the major contributor to job performance.

As per the results, this study provides valuable insights to policy makers and educators who are interested in finding the factors that contribute to employees' job performance and work-family balance. Finally, further research and limitations are discussed.

Key words: Work-family balance, Time balance, involvement balance, satisfaction balance, Job Performance, Gender, Marital status, Dependent children. 


\section{CHAPTER ONE}

\section{Introduction}

\subsection{Background of the study}

There is a growing interest among all categories of work regarding balance of work life and family life (Grzywacs and Carlson, 2007). It implies that the field of work-family balance increasingly important for employees who are seeking balance between their work roles and family roles. The term work-family balance is defined by many people in different ways. Work-family balance in simple terms can be defined as the balance between works related roles and family related roles. According to Clark (2000) workfamily balance is defined as "satisfaction and good functioning at work and at home, with a minimum role of conflict" and Grzywacz and Carlson (2007) define it as "accomplishment of role related expectations that are negotiated and shared between an individual and his or her role related partners in the work and family domains". Both definitions focus on satisfactory conciliation between work and family. On the subject of human resource management, the concept of work-family balance acquires a very significant place. Many scholars have conducted various studies on the relationship between work and family under different names, such as work-family enrichment, work-family conflict, work-family integration (Carlson et al., 2004; Gatta and Roos, 2004).

Within an ever changing market economy the father's traditional breadwinner role has changed. Consequently, in most organizations, numbers of female workers changed increasing and at the same time, new concepts have emerged, such as dual earner couples. As mentioned by Hill et al. (2003) "workforce includes more dual earner 
couples who have responsibility for the care of children and elderly dependents". Parenthood is one factor in family demand and there are many other factors that affect family balance. Unlike in the past, both men and women are achievers in higher education and they are not engaging in jobs, but in careers as professional parents (Hill et al., 2003). "Increased labor force participation of women" is a major challenge and their traditional role at home has changed (McGovern, 2009).

Work-family balance is a challenging issue for many working adults, who are working with many organizations. As stated by O'Laughlin and Bischoff (2005) balancing parenthood and career is very challenging for all professionals who engage in careers. When both of parents involve in their work, they have to face time pressures and have to confront an overlap between work and family. People who have engaged in careers other than jobs have more expectations. It shows that the development of the work may cause trouble in people's lives. "When the demands of the work and non work domains are mutually incompatible, conflict may occur" (Sturges and Guest, 2004). In order to find solutions many studies have given their attention to this vast subject area.

\section{Work-family balance in Sri Lanka}

Sri Lanka is a male dominated country (Nanayakkara, n.d) and at the present time it is changing into dual career families. According to the Department of Census and Statistics of Sri Lanka, female participation in employment of 2013, the first quarter was $37 \%$ and this shows an increase of $2.6 \%$ in comparison to 2010 . Because of the dual earner concept both male and females have to struggle with their time to find a balance between work life and family life. Most countries around the world have implemented several alternative work schedules to achieve work and family balance 